Por diversas razones, el pronombre ha sido slempre uno de los temas más controvertidos de la lingưística española. Muchas son las cuestiones por considerar, atinentes a su naturaleza ${ }^{1}$, a las que se suman otras que tiene que ver con las distintas posibilidades de realización en el habla. Entre ellas se destacan las relacionadas con las formas personales átonas ${ }^{2}: \underline{m e}$, te, $10(s), 1 a(s)$, nos, $\mathrm{se}^{3}$, que tendremos en cuenta en esta oportunidad ${ }^{4}$.

Nos basaremos exclusivamente en la observación di recta de la realidad lingüística del $\mathrm{NOA}^{5}$, sin atender los ejemplos procedentes de obras literarias ${ }^{6}$, en el afan de registrar el auténtico uso cotidiano. Al respecto anticipamos que no se presentan mayores diferencias en el empleo de los clíticos de provincia a provincia. Por lo cual sólo se destacará a qué lugar corresponde, en caso de que se observara alguna particularidad. De lo contrario las consideraciones se harán a nivel regional ${ }^{7}$.

Es decir que, partiendo de la premisa de una cierta homogeneidad linguístico-geográfica en la utilización de estas formas, prestaremos atención a otros factores que tienen parte activa en su realización en el NOA:

1) En relación a los pronombres: a.-su posición respecto al verbo; b. - el comportamiento sintáctico. (objeto directo, indírecto o predicativo); c.- la duplicación de objetos; d.-su función deltica.

2) En relación a los verbos que se emplean con ellos: su transitividad o intransitividad.

3) En relacíón al acto de habla (a los cuales Ana Marfa Barrenechea y Teresa Orechia llaman "rasgos propios del hecho comunicativo" 8 (a. - la distribución sociocultural de los hablantes; b. - la afectividad. 


\section{ME TODOLOGIA}

\subsection{Acerca del material utilizado}

El material que se analiza en este trabajo proviene de $\mathbf{7 2}$ encuestas (33 horas de grabación), realizadas equitativamente a informantes nativos, en su mayoría, o por lo menos con 10 años de residencia en alguna de las provincias del NOA.

Se trata de gente de ambos sexos, cuya edad oscila entre los 16 y 75 años y desempeña distintos oficios o profesiones.

Se distinguieron tres niveles socioculturales (alto, medio, bajo)de acuerdo con el grado de educación de los informantes. En el alto se ubicaron -en general- personas con estudios universitarios, preferentemente humanísticos, o lectores asiduos, aún sin educación superior; en el medio, a maestros sin gran dedicación, bachilleres, estudiantes universitarios de los primeros cursos o profesionales técnicos; en el bajo, a gente de escasa cultura, con sólo algunos estudios primarios y a los analfabetos ${ }^{9}$.

\section{POSICION DE LOS CLITICOS RESPECTO DEL VERBO}

\subsection{Anteposición}

El pronombre átono suele aparecer antepuesto al verbo en la mayoría de las circunstancias ${ }^{10}$, tanto con formas verbales simples $^{11}$ como con las perífrasis; ya sea en función de objeto directo o de indirecto.

Esta posición del clítico es una de las posibilidades de nues tra lengua ${ }^{12}$. Al respecto dice Ch. Kany: 'En el español tipo, los pronombres complemento pueden ir delante de un verbo auxiliar (lo voy a hacer) o funcionarse con el infinitivo subordinado (voy a hacerlo). El primer caso predomina en la conservación, el segundo en el uso literario"13.

\subsection{Duplicación de objetos}

Es frecuente que los átonos anticipen a los objetos directo 
o indirecto representados por pronombres tónicos o sustantivos, a los que precede la preposición a. Esta construcción suele llamarse "redundante" o "pleonástica"14, y ha sido comentada por los lingưistas en numerosas oportunidades, algunas veces con opiniones dispares 15 .

El mayor problema se presenta en cuanto a la determinación de cuál es el elemento que debe considerarse redundante en este tipo de construcciones. Evidentemente, ello suele depender dd contexto que rodea al clítico. Pues si bien estamos de acuerdo con las observaciones de Ana María Barrenechea y Teresa Orecchia ${ }^{16}$ en cuanto a que, cuando aparece un sustantivo en la construcción en que está presente el pronombre átono, el básico es aquél, debemos tener en cuenta que no ocurre asi cuando en un relato, por ejemplo, se ha venido haciendo referencia a ese nombre en las cláusulas anteriores. En tal caso, su aclaración por medio de un objeto directo sustantivo tendría sólo el valor de un refuerzo del pronombre átono ${ }^{17}$.

Esa es la situación que se presenta en relación al objeto directo e indirecto con todas las formas átonas a excepción de $\mathrm{se}^{18}$, que por su invariabilidad de género y número, precisa del énfasis determinativo de un sustantivo o de la forma tónica correspondiente (a él, a ella, a ellos, a ellas).

Si bien la mayor cantidad de ejemplos se ha registrado en el habla de informantes de los niveles medio $(43 \%)$ y bajo $(37 \%)$, del total de 478 duplicaciones que aparecen en las grabaciones, también se encuentra un número considerable de casos en el nivel alto $(19,91 \%) 19$.

Por otra parte, 450 de estas formas señalan catafórica mente hacia el objeto que duplican 20 . Por ej.:

"Yo lo quiero ver a él." (N. medio)

"¿ Los vas a visitar a los Diaz?" (N. medio)

"¿Creés que la voy a convencer a tu vieja ?" (N. bajo)

"Ahora te lo voy a contar todo sólo a vos." (N. alto) 
"No me vengas a decir a mí que eso no es verdad. "(N.medio) "Digame: ¿no se lo advertí a Ud.que no lo hiciera ?"(N.alto)

"No se lo voy a decir a nadie." (N. bajo)

3. ACERCA DE LO, LA, LE

3.1. Su comportamiento sintáctico

3.1.1. Objeto directo y objeto indirecto

De acuerdo con los resul tados de la investigación de campo, podemos afirmar que en toda la región noroeste de la Argentina se usan los pronombres $\underline{10}^{21}$ (masculino) y la (femenino), para el objeto directo de persona o cosa, de manera general, en los niveles socioculturales medio y alto. El empleo de le para esta función se registra de manera reducida: el $2 \%$ del total de 780 casos de objeto directo con pronombres átonos. Le es utilizado casi exclusivamente como objeto indirecto 22 . Los ejemplos de leísmo registrados en el NOA, corresponden a ancianos del interior de las provincias de Catamarca, Santiago del Estero y Tucumán.

\subsection{Anomalía genérica}

En Santiago del Estero, principalmente, y en Tucumán en la zona limítrofe que recibe la influencia de esa provincia ${ }^{23}$, se observa falta de concordancia genérica ${ }^{24}$ entre la forma pronominal masculina ${ }^{25}$ y el objeto directo expresado por medio de un sustantivo femenino. La deixis del clítico es siempre catafórica. Encontramos 28 ejemplos entre hablantes de nivel bajo y 14 del medio. Veamos:

"Lo reta mucho a su hija." (N. bajo)

"¿Al final me lo va hacer la pollera?" (N. medio)

"Lo baña a la chiquita una vez por semana." (N. bajo)

\subsection{Señalamiento sin objeto definido}

3.3.1. Se observan otros casos de aparente anomalía, que en realidad podría tratarse de un señalamiento del pronombre hacia un objeto supuesto, ausente de la oración, y no hacia el elemento gramatical que parece indicar ${ }^{26}$, si es que se expresa alguno. 
Pues la alternativa seria: a) que seffale hacia un objeto supuesto, ausente en la oración o b) que sea una forma vacía de significacion, que sirve únicamente para intensificar la accín. Se han registrado en total 53 ejemplos.

"Los dlas estuvieron horribles, pero yo lo pasé blen. "(N.alto)

"I Te la regalo, también! " (N. medio) despedida 27 :

O en.construcciones más simples, como las f6rmulas de

"Que lo pasen blen."

"Que lo pasen hermoso." (Indistintamente en cualquier nivel)

3.3.2. Por otra parte, vemos que le, enclitico a verbos en Impe rativo o a algunas interjecclones aparece vacio de conteni$\mathrm{do}^{28}$, formando construcciones interjectivas con distintos matices. Se reunieron 39 ejemplos, de los que corresponden 27 a nivel bajo, 10 a nivel medio y 2 al alto:

"dale" "déle" "metéle" "rufale" "Epale"

3.3.3. Asimismo se emplea le en una construccion fija más perffrasis verbal con hacer en infinitivo. Kany oplna que tendria el valor de 'con ello'29. La frase expresa resignaci6n ante determinada clrcunstancia que no puede cambiarse ni soluclonarse. Se usa indistintamente en todos los niveles socioculturales:

"qué le vamos a hacer!"

\subsection{Anomalfa numérica}

3.4.1. Son varias las posibilidades que ofrecen los verbos en plural, en relacion a los enclíticos que cumplen funcibn de objeto directo o indirecto.

Con las formas de presente de subjuntivo en tercera persona (en concordancia con Uds.), que se utlizan como imperativo, se produce un fenómeno que se repite en gran parte de la Argentina. Se trata de la adicibn, al enclítico, de una $-n$ analogica, debida -seguramente- al sentimiento popular de que si el verbo esth en plural, le corresponde tal desinencia a la forma en que se encuentra; sin reparar en que, lo que se interpreta como terminaci6n 
verbal, es en realidad un pronombre clrcunstancialmente ligado.

Otra consecuencia de esta unión es la acentuación del clítico, en la mayoría de los casos 30 .

3.4.1.1. Cuando el enclítico es uno solo, seobservan dos posibilidades en el habla tanto del nivel sociocultural medio como del bajo, en ambos estilos (informal y formal). De un total de 187 casos de formas verbales exhortativas con pronombres lo, la, le 0 se enclitico, encontramos 53 ejmplos en que se ha producido la metátesis de la $-\mathrm{n}$ del verbo al clítico $\mathrm{lo}_{\text {, }}$ frente a 17 en que el verbo conserva su desinencia pero se adiciona otra $-\mathbf{n}$ al pronombre. Respecto a la, encontramos 29 para el primer caso y 12 para el segundo. Con le, 16 para el primero y 10 para el segundo, y con se, 23 para el primero y 18 para el segundo. En cambio dice Kany que "En el habla rústica y vulgar de España (Castilla, Aragón), la -n sólo se añade a se y a me en las formas verbales imperativas e infinitivas, pero, al parecer, no se añade a leo a lo como en mu chas partes de América, donde, a su vez, el-lon es raro, salvo en la zona del Río de la Plata'"32.

Veamos algunos de los ejemplos recogidos:

cortelón cortenlón mirelén la cara mirenlén la ropa paselán pasenlán sequelén la nariz sequenlén la ropa miresén mirensén 33

3.4.1.2. Cuando se unen al verbo dos cliticos, se dan las sigulentes alternativas. Las formas que llevan $-\underline{n}-\underline{-n}-\mathbf{y}-\underline{n}$, corresponden, en especial, al hablal informal del nivel medio:

\begin{tabular}{|c|c|}
\hline $\begin{array}{l}\text { cuidemelon } \\
\text { miremelon } \\
\text { muevamelan }\end{array}$ & $\begin{array}{l}\text { cuidenmelonn } \\
\text { mirenmelón } \\
\text { muevanmelán }\end{array}$ \\
\hline
\end{tabular}

\subsection{Concordancia numérica en relación a le}

Vemos a menudo la vacllación en cuanto a la concordancia nymérica del pronombre atono le y el objeto de persona o cosa al cual sefala. Se trata de uma forma muy extendida no s6lo en His- 
panoamérica, sino también en Espana ${ }^{34}$. José Joaquín Montes estudia el caso en relacion a Colombia y plantea la posibilidad de que se trate de un sintoma de economia ${ }^{35}$.

El 90\% de los ejemplos registrados en la regibn del NOA corresponden a hablantes de los niveles medio y bajo:

"Le cantó tres verdades a los tipos esos." (N. bajo)

"Le ordenaron a todos que se retiraran." (N. medio)

"Le puso varias tachuelas a los tablones." (N. bajo)

\subsection{Lo como predicativo}

Otra funci6n en que aparece el clítico lo, si bien no tan frecuentemente como en los casos del objeto directo y del indirecto, es la del predicativo ${ }^{36}$. Se han registrado 9 ejemplos: 4 en el habla de nivel soclocultural alto; 3 en el medio y 2 en el bajo. Slempre presenta una deixis anafórica ya que, por medio de las clásulas que lo incluyen, se ratifica algo expresado anteriormente en el diálogo. Por ejemplo:

"La persona indicada es Fernández." "SI que lo es."

"-Pienso que es un chico educado y estudioso. ¿ Qué opina Ud?"

"-SI, por supuesto; $\underline{10}$ es $\underline{10}$, es."

\section{ACERCA DE SE}

Consideramos por separado esta forma, debido a que, no obstante coincidir varlas de sus caracterfsticas con las de los otros cliticos, algunas le son propias y precisan un tratamiento individual $^{37}$.

\subsection{Su comportamiento sintactico}

\subsubsection{Se oblicuo}

Esta posibilidad de se, que Cantero Sandoval ubica en el grupo Pronominal38, o sea de las formas que desempeñan en la oraci6n el papel de objeto directo, indirecto, etc., permite ver 
cбmo unaf orma pronominal (Be) toma el lugar de otra del mismo origen $^{39}(\mathrm{le} / \mathrm{s})$, cuando precede en la oración a los clíticos lo/8 o 1n/e.

Puede aparecer en una construcción simple: "se lo mostré", o duplicada: "Se lo dl a Marlo". Pero este típo de cláusula con desdoblamlento del objeto no es tan frecuente como casos similares en que intervienen las otras formas pronominales. Sblo se han registrado 17 ejemplos, 9 de señalamlento catafórico y 8 anaforico. Entre ellos:

"A mils chicos no se jo cuenten, por favor." (N. alto)

"A los dos se lo he dicho varias veces." (N. medio)

"jOtra vez_se la prest a ellos!" (N. bajo)

De acuerdo con lo observado en relación a algunos casos que aparecen en los informes recogidos, los grupos se lo, se la pueden alternar con le cuando hay duplicación del objeto indirecto. Por ejemplo:

"A mis chicos no les cuenten, por favor."

"A los dos les he dicho varias veces."

\subsection{Se no pronominal ${ }^{40}$}

\subsubsection{Pasiva impersonal}

En este tipo de construcclones se aparece antepuesto a un verbo transitivo que concuerda en número plural con el sujeto paclente. Los casos registrados corresponden al nivel soclocultural alto (63\%) y medio (32\%), de un total de 163 ejemplos con se más verbo transitivo. Veamos algunos:

"Se rifan dos automóviles." (N. alto)

"Se omitieron los principales f a c tores del desastre." (N. alto)

"Todos los dfas se rezan oraclones al Sefior de la Salud." (N. medio) 


\subsubsection{Activa impersonal con se}

ambigua.

Esta formación con se puede ser transitiva, intransitiva o

4.2.2.1. Se observa la presencia de se en oraciones impersonales cuasirreflejas activas, que ofrecen muchos casos en el habla diaria, en los pertodlcon y en la propaganda en general. Encontramos 67 efemplos on lastrabaciones realizadas en el NOA.

El pronombre se actua como determinante del verbo ${ }^{41}$, en la pasiva cuasir refleja, y como signo de impersonalidad con el verbo en voz activa y el objeto directo en plural ${ }^{42}$. Por ejemplo:

"Se compra diariog viejos." (N. bajo)

"Se levanta puntos de media." (N. bajo)

"Se dio a conocer log nuevog planęg." (N. medio)

4 2.2.2. En otros casos el verbo puede ser intransitivo o transitivo, sin objeto directo. Los ejemplos de este tipo ocupan el 74\% de las oraciones impersonales activas. Algunos de ellos son:

"Por el río se llega hasta la selva."

"En los valles se duerme muy bien."

"En esta época no se vende en ningín negocio."

4.2.2.3. Por último están las construcclones en que se precedel a un verbo en singular $y$ un elemento nominal (sin preposición a) en singular. Les corresponde el $47 \%$ del total de las impersonales cuasirreflejas. Por ej.:

"Se promociona la cultura durante todo el afio."

"Proximamente se anunciar la focha exacta."

"El vlernes se desratlzarí la Facultad."

5. Particularidades comunes a varios cliticos 


\subsection{Oracion impersonal con pronombre reflejo y verbo hacer}

Una de las expresiones que llama más la atención de los hablantes forḱneos a la region es la compuesta por un pronombre atono intensivo y el verbo hacer con valor impersonal. Por medio de ella se indican distintas sensaciones de temperatura en los tres niveles socioculturales, en el estilo familiar de todos los días 43 . Se registraron 24 casos de este tipo:

"Me hace mucho frio para salir." (N. alto)

"Seguro que te hace calor." (N. medio)

"Me preocupa porque le va a hacer frío." (N. alto)

"i Roguemos que no nos haga frio!" (N. bajo)

Se trata de una particularidad que esth, como dice F. Pals, "ahíta de valor expresivo"44, pues mediante el empleo del clítico se aporta afectividad a la oracibn impersonal, al indicar que el frío o el calor, que pueden ser sentidos por todos los residentes de un lugar, se produce -sin embargo-, "especlalmente" para ml. Soy yo, u otra persona determinada, quien lo slente en particular, y la fuer za de este sentir lleva a que el hablante lo exprese de este modo .

\subsection{Construcciones pseudo-reflejas}

Además de los casos corrientes del español, en que los cliticos aparecen como reflexivos (se registraron 213 ejemplos) o recíprocos (93 ejemplos), encontramos muchas formas en las que se detacan como mero signo de reflexividad o como pronombres enfiticos.

\subsubsection{Expresiones exhortativas}

5.2.1.1. La forma pronominal refleja nos se maniflesta como proclitica en expresiones exhortativas empleadas en todos los niveles socioculturales de Tucumán y otras provincias del NOA, de manera distinta de cómo se da en el resto del pals ${ }^{45}$, donde aparece enclítico ${ }^{46}$.

T. Navarro Tomás también señala este ordenamiento para otras personas gramaticales ${ }^{47}$; pero en el NOA en general se re- 
gistra únicamente con la primera persona plural ${ }^{48}$.

En las grabaciones se encuentran 63 ejemplos de este tipo, mientras no aparece ninguno con el pronombre enclitico. Estan distribuidos indistintamente entre hablantes de 108 tres niveles socioculturales. La curva de entonacion interrogativa hace sentir mayor gentileza en la expresibn:

"Nos vayamos, ¿querés?" (N. medio)

"Nos paremos rápldo." (N. bajo)

"¿Nos camblemos de lugar. ?" (N. alto)

\subsubsection{La primera persona plural del verbo con se proclítico}

En el habla rustica y en la urbena de nivel soclocultural bajo, se observa el empleo del clíticose en vez de nos, con formas verbales de la primera persona plural:

"Apenas se fuimos, ellos llegaron."

"Che, se vayamos temprano."

"Sl se hemos visto dos veces, es mucho."

"¿Se levantamos ya?

El origen de este uso es incierto, ya que no se da s6lo en el Noroeste, sino a lo largo del pats, hasta en la Provincia de Buenos Alres ${ }^{49}$.

\subsubsection{Pronombres átonos intensivos con verbos transitivos}

El pronombre átono intensivo se usa mucho en toda la región del NOA, cuya habla -como toda habla provinclana- aparece re cargada de matices afectivos.

\subsubsection{Dativo ético 50}

Un caso de gran extensíon, que se da en el habla de estilo informal en todos los niveles socioculturales es el del dativo ético. Desde el punto de vista gramatical no tiene razbn de existir, pero el hablante lo usa con el fin de hacer más vívida su presencia o la 
del prójimo en la oracion. Se han registrado 193 formas en la regi6n. Por ej.:

"AsI no juego. ISiempre se agarra la mejor parte! "(N. bajo)

"¿Cuántos vestidos te has hecho este mes? Tu modista no debe de dar abasto." (N.alto)

"¿Querés que me coma el último pedazo?" (N. medio)

\subsubsection{Dativo ético (intensivo)-objeto directo duplicado}

Asimismo es frecuente -en el habla familiar e intima de los niveles socioculturales medio y bajo- el empleo del pronombre átono intensivo en función de dativo, antepuesto a un objeto directo pronominal, en oraciones con verbos en tercera persona con valor impersonal.

Es indudable que mediante la duplicación de los clfticos objeto directo se imprime mayor sentimiento a la expresion. Dicha fuerza parece acrecentarse más con el pronombre de primera persona, al destacarse la subjetividad del hablante. (Se registraron 33 ejemplos). Veamos algunos:

"Tengo miedo de que me lo vayan a confundir al reloj." (N. medio)

"¿Vos creés que me lo devolverán hoy al recibo?"(N.medio)

"Señorita, ¿ya me la han buscado a la libreta?" (N. bajo)

\section{2.4. Con verbos intransitivos que actian como transitivos}

\subsubsection{Dativo intensivo - acusativo intensivo}

El matiz afectivo de los pronombres atonos pleonf́sticos hace que 108 verbos intransitivos que acompanan actien como transitivos.

Para el sentimiento del hablante no tiene importancia la naturaleza del verbo que se emplee. La emotividad supera los límites gramaticales y se impone en la construcci6n ${ }^{51}$.

El camblo de naturaleza del verbo se hace más evidente cuthe heva un pronombre como objeto directo ${ }^{52}$ y otro pronombre 
átono en función de indirecto.

Este fenómeno tiene lugar principalmente en el habla de gen te de los niveles socioculturales medio y bajo. Se han encontrado 39 ejemplos de este tipo, distribuidos equitativamente en la región. Por ej . :

"Me gusta esta pollera. Me la quedo." (N. medio)

"l Ay, ay! Ayudáme que se me lo cae. ${ }^{153}$ (N.medio)

"Me lo han dormido de un golpe." (N. bajo)

"Tené cuidado que no se te lo rompa." (N. medio)

"Apuráte que se me la va." (N. bajo)

5.2.4.2. Algunos verbos cambian, por analogía con otros de significación semejante. Así se producen construcciones si milares con pronombres atonos intensivos, a pesar de que un verbo sea intransitivo y el segundo transitivo:

"No me lo acuerdo." ('No me acuerdo de él')

"No me lo recuerdo" ('No lo recuerdo')

Obsérvese que se ha producido un cruce de posibilidades entre los dos verbos. El primero ha tomado un acusativo intensivo ${ }^{54}$ el segundo un dativo intensivo.

Ambas construcciones alternan en todos los niveles.

5.2.4.3. Existe otro caso de acusativo intensivo muy difundido en el NOA. Se trata de una forma totalmente vacia de signifícación, sin objeto ni siquiera supuesto, que sirve únicamente para intensificar la acción verbal. Se han registrado en la región 74 formas. Veamos algunas, todas con el clftico las:

"No sé de qué se las da." (N. alto)

"Ahora se le dio por tirárselas de grande." (N. bajo)

"Se las ingenió para engancharme." (N. medio)

\subsubsection{Con verbos intransitivos}




\subsubsection{Dativo intensivo}

El caso más común de dativo intensivo con verbos intransitivos cuasirreflejos es el que lleva las formas pronominales atonas de primera, segunda y tercera persona ${ }^{55}$, con valor intensifica dor.

Los ejemplos que se proporcionan a continuación fueron tomados del habla de los distintos niveles:

"१Mirá! Se te derritió la manteca" (N. medio)

"Se nos derramó toda la botella de vino". (N. alto)

"Se le corrió un punto a la media." (N. bajo)

5.2.5.2. Así como en el caso anterior el sujeto es slempre una cosa inanimada, también puede desempeñar esa función una persona. La forma pronominal que actúa como dativo intensivo suele ser de tercera persona. Se han registrado ejemplos en el habla de los tres niveles socioculturales:

"Se les guiso hacer el vivo."56 (a, ante ellos) (N. medio)

"isi te les escapás a tiempo, te felicito." (a, de ellos) (N. alto)

"Me le burlé en las narices " (a, de él) (N. bajo)

5.2.5.3. Una fórmula de saludo que ofrece afectividad es cómo le va, usada por gente de todos los niveles socioculturales en el estilo familiar e intimo.

Se trata de una forma cariñosa que se dirige, en el habla familiar y amistosa, a personas que merecen nuestro aprecio. Corresponde al pronombre de usted y no tiene equivalente para usar con vos. El le, lejos de significar respeto o distancla, aporta un matiz afectuoso, mientras me lo refuerza, acercando hacia el hablante a la persona a quien se saluda.

\subsubsection{Verbos intransitivos con pronombres reflejos}

El empleo de los pronombres reflejos con verbos intransi- 
tivos es tan común en Hispanoamérica, que muchas construcciones de este tipo suenan ya normales al ofdo culto.

5.2.6.1. Algunos de los verbos son: enfermar, reír, volver, entrar, amanecer, tardar, subix, bajar, aparecer, etc. ${ }^{57}$. Kany comenta que las formas cuasirreflejas que integran se usaron mucho más en el lenguaje de siglos pasados que en el de hoy en España. Sin embargo, en América están acutalmente muy extendidas. En nuestra región se recogieron 298 casos.

A continuación ofrezco algunos ejemplos recogidos del habla del NDA y que se usan en todos los niveles:

"E. se enfermó de golpe. ${ }^{158}$

"Reíte nomás vos."

"¿ Te has vuelto desconfiada ?."

"Se amanecía haciendo cuentas."

"Subite a la silla."

"Se bajan inmediatamente o procedo."

5.2.6.2. Asimismo son comunes las construcciones con estar como cuasirreflejo, probablemente por analogta con que darse, en los niveles socioculturales medio y bajo:

"Estáte aqui hasta que vuelva." (N. medio)

"Pero vos no te estás quieto ni un minuto." (N.bajo)

"SI, me estaré calladita." (N. medio)

\subsubsection{Verbos transitivos con pronombres reflejos}

Del mismo modo hay algunos verbos transitivos que se usan como cuasirreflejos. Tenemos, por ejemplo, el caso de saber 0 poder:

"Sabéte que no lo voy a hacer."

"No lo puedo al tipo ese."

Kany hace referencia a verbos que son transitivos en Espana, como dilatar, demorar, atrasar, adelantar, y que en América 
se presentan como cuasirreflejos ${ }^{59}$. Se usan en todos los niveles socioculturales:

"La reunión se dilató mucho." (N. alto)

"No me demoraré." (N. medio)

"¡Ufa! ¡Otra vez se me adelantó el reloj." (N. bajo)

\section{Conclusiones}

De acuerdo con el panorama que ofrece el empleo de los clí ticos en el NOA, podemos arribar a las siguientes conclusiones:

a) Muchos de los usos pronominales atonos que se registran en el NOA se extienden por gran parte del país, de América y hasta de España.

b) Pero a la vez se encuentran algunos casos propios de las provincias del NOA ("Me hace frío", "¿ Nos sentemos?", etc.), por medio de los cuales el hablante expresa su afectividad.

c) Los clíticos lo, los, la, las son los que registran mayo $r$ cantidad de casos en el habla del NOA.

d) La mayoría de las formas en las que intervienen los pronombres átonos tiene cabida en el habla de los tres niveles socioculturales: alto, medio, bajo, en estilo familiar.

e) Es necesario brindar toda la información posible sobre los distintos aspectos pronominales, a fin de tratar de establecer las áreas de extensión de cada fenómeno en nuestro país. 
1 Hasta se cuestiona su denominación. Véase al respecto la propuesta del nombre de "enunciador" que hacen S.M. García y María Julia Alonso, en Estudios gramaticales, "El Pronombre", ed. Biblos, Buenos Aires, 1981.

2 Dice Teresa Echenique Elizondo en "El sistema referencial en el español antiguo: leísmo, laisma y loísmo", RFE, LXI, 1981 , p. 113, "La confusión en el empleo de las formas átonas de los pronombres personales es un hecho linguístico que caracteriza al español frente a las demás lenguas románticas: ningún hablante de otro idioma vacila en el uso de los pronombres correspondientes. El leísmo, el lafsmo y el loísmo son fenómenos típicos de la lengua española y producto, como es bien sabido, de la alteración del uso etimológico originario a causa de la confusión producida entre las formas de acusativo y las de dativo".

3 En el español peninsular debe tenerse en cuenta también os que prácticamente ha desaparecido en América. Comenta Nélida Donni de Mirande, en "Aspectos del español hablado en la Argentina", en Linguística española actual, II, 2, Ma drid, 1980, que "En los pronombres con función de objeto las formas correspondientes a 'vosotros' también han sido reemplazadas por aquellas de 'ustedes' perdiéndose asi 'os' sustituida por 'te', a causa de la presión analógica de 'me' y 'se', analogía que tamblén actúa en las formas vulgares 'los' y 'se' (reflexivo) por 'nos'".

4 El presente trabajo forma parte de una investigación más amplia que comprende las distintas clases de pronombres, la que -a su vez- integra el programa sobre "Niveles sociolingüísticos en el habla de Tucumán y en la Literatura del NOA" que, bajo mi dirección, desarrolla el equipo de Lingǘstica del Instituto de Investigaciones Lingüisticas y Li- 
terarias Hispanoamericanas de la Facultad de Filosoffa y Letras de la UNT.

Esta región comprende Jujuy, Salta, Tucumán, Santiago del Estero. Además de las encuestas, que fueron dirigidas y semidirigidas, se tomaron datos de conversaciones libres.

Algunos trabajos, como el de Vicente Pérez Sáez Esquema para el estudio del habla de Salta, U.N. de Salta, Sa l ta , 1975, se basa en ejemplos de obras literarias de la región.

Véase la interpretación de Vicente Pérez Sáez en Op. cít. p.p. 2-3 acerca de "regionalismo", a la cual nos atendremos.

Cfr. Ana María Barrenechea y Teresa Orecchia, en "La du plicación de objetos directos e indirectos en el español hablado en Buenos Aires", en Estudios linguilisticos y dialectológicos, Temas Hispánicos, Ed/Hachette, p. 74 .

Se sigue esta clasificación en todos los trabajos que se llevan a cabo en el Instituto de Investigaciones Lingüirsticas y Literarias Hispanoamericanas, a partír de mi libro America nismos usados en Tucumán I, Cuadernos de Humanitas: 48, UNT, Tucumán, 1976 .

10 Se observa esta posición en el $73 \%$ de los casos de pronombres atonos.

11 Comenta Susana Boretti de Macchi, en E1 espaniol hablado en el litoral argentino. El pronombre, Consejo de Invest . Univ. Rosario, 1977, 1.1.2.2.1./2.: "En la colocación de pronombres átonos con respecto al verbo, el uso general, tanto en lengua culta como popular, los muestra antepuestos. / Con frase verbal alternan las formulas pron. + frase verbal / Frase verbal + pron.". Véase en cuanto a la colocación del pronombre el artículo de Elizabeth Luna Trafll, "Sobre la sintaxis de los pronombres atonos en construcciones de infinitivo", en Estudios sobre el español hablado 
en las principales ciudades de América, UNAM, México 1977, p. 105-113.

12 Véase S. Gili y Gaya, Curso superior de sintaxis española, Ed. Spes, Octava ed. Barcelona, 1973, p. 174.

13 Véase Ch. Kany, Sintaxis Hispanoamericana, ed. Gredos, Madrid, 1969, p. 160 .

14 Véase Gill y Gaya, Op.cit., $\not 174$

15 Ana María Barrenechea y Teresa Orecchia, Op.cit. p.73 101 , coinciden con la opini6n de Keniston $(1937 / 8,62)$ y Poston $(1953, H 4.7)_{2}$ en cuanto a que en estos casos las formas redundantes, en relación a sustantivos, son los pronombres atonos; pero difieren de parecer cuando se trata de duplicación de pronombres. Dicen: "Hemos estudiado en las grabaciones las combinaciones posibles ("sustantivo " solo, "sustantivo" + pronombre personal, pronombre personal solo, pronombre personal + pronombre personal) y hemos llegado a la conclusión de que cuando aparecian. "sustantivos" éstos no eran redundantes, es decir que no se los podia suprimir o sustituir por pronombre personal sin alterar el significado del mensaje.... Esto nos confirmb́ en la idea de que el sustantivo debía ser considerado como basico y el pronombre personal atono que lo acompaña en el mismo texto como refuerzo" $(H 0.2)$, En cambio "hemos comprobado que las encuestas analizadas no registran ob jetos representados sరlo por pronombre tónico (sin forma átona conjunta), y en cambio hay centenares de casos a la inversa (751 atonos sin duplicación). Esto nos ha llevado a pensar que para reflejar verdaderamente el comportamiento de los hispanohablantes con respecto a la duplicación de pro nombres personales es necesario clasificar a los átonos como básícos y a los tónicos como realce que se les agrega" $(\not / 0.2 .1$.$) . Al respecto, Inés A$. de Quant y J.M. Irigoyen en Interferencia guarani en la morfosintaxis y léxico del es pañol substandard de Resistencia, Facultad de Humanidades, Resistencia, Chaco, 1980, $\not 1.2 .5 .2$., hacen la observa- 
ción de que ésta no es la situación que se da en Resistencia.

17 Afirma Vicente Pérez Sáez, Op.cit., p.26, respecto a la oración "Ya lo tenemos a Calixto Gauna galopando": "Si un historiador está contando la hazaña de Calixto Gauna y dice 'Ya lo tenemos galopando', no puede haber dudas acerca de la persona a la que se refiere el pronombre "lo". Lo redundante entonces es la aclaración posterior "a Calixto Gau na" ".

18 Observa S.Gili y, Gaya, Op.cit., $\$ 174$, que "La indeterminación del personal se invariable para el género y el número, suele corregirse añadiéndole una forma tónica del mismo pronombre: se lo di a él, a ella, a ellos, a ellas, a Luisa. Los matices son muy variados según los casos; pero aunque a menudo parezcan un simple pleonasmo propagado por analogía, las formas tónicas en apariencia redundantes adquieren también con frecuencia significado propio, lo cual nos hace guardarnos de considerarlas en todos los casos como una mera repetición del mismo complemento".

19 Como es de suponer, debido a que el corpus a que recurrimos para este estudio corresponde a hechos de habla, en cada caso influyen varios de los factores citados al comienzo. De modo que, no obstante tomar como eje los clíticos en sí mismos y su comportamiento sintáctico, conjuntamente se harán las observaciones correspondientes a los aspec tos que se destaquen en cada caso.

20 Noemf G. L. de Terán y M.E. Asis, en "Uso del pronombre personal átono lo", Primeras Jornadas Nacionales de Dialectologfa, U.N.T., Tucumán, 1983, p. 299, opinan que "Los casos de redundancia pronominal están generalizados en América en la lengua hablada y escrita de todos los niveles socioculturales, no sólo con referencia a personas sino también a cosas. En general predomina el pronombre re dundante catafórico, es decir, el que tiene valor anticipativo." 
21 Dice T. Echenique Lizondo, en Op.cit. p.113, que en Hispanoamérica 'To es la forma más extendida para la función directo masculino singular, si bien no la única, de modo que la alternancia entre lo y le corresponde -segín parecea la lengua escrita $y$, ocasionalmente al habla culta, sin que afecte al habla popular que utiliza siempre 10."

22 El leísmo se da en la Argentina sólo en Corrientes, Misiones, parte de Formosa y el Chaco. Afirman I. Abadia de Quant y José M. Irigoyen, en Interferencia guaraní en la morfosintaxis y léxico del español substandard de Resio tencia, Facultad de Humanidades, Resistencla,Chaco, 1980, \#1.3.3. , que "Sigulendo el modelo guaranf en español subotandard no se observa distinción formal entre el objeto directo $\mathrm{y}$ el objeto indirecto, tereera persona proniominal, singular y plural. /En el español substandard de Resistencia, se utilizan con frecuencia las formas etimologicas del objeto indirecto -le, les-, por las del objeto directo referido a personas y animales indistintamente para masculino y femenino singular y plural: lo, la, los, las. Tambiên se observa la forma pronominal le, para el acusativo singular, masculino y femenino -lo, la-, referido a cosa." Véase además Hugo Amable, El lésmo misionero, Univ. Nac. de Misiones, 1980.

23 Ch. Kany, en Op.cit., p. 139, afírma que " en algunas zonas indígenas el lo es el único complemento directo de la tercera persona del singular que los indios incultos em plean para el masculino y femenino tanto de persona como de cosas." Y en p. 149: "Este lo redundante parece ser la regla, especialmente en el bajo pueblo andino, incluso cuando el complemento directo lo constituye una cosa. Además, no sólo los Indios iletrados, síno también otras personas con cierto grado presumible de cultura, a veces emplean el lo prescindiendo del género o número del nombre complemento directo, posiblemente para prestar valor afectivo a la frase o para redondearla."

24 N.A. Gómez López de Terán y M.E. Asís también ofrecen 
en Op.cit., p. 300, un caso de anomalla numérica con lo, que nosotros no registramos en nuestra investigación: "Y lo sacó a los cerdos del corral."

25 En algunos casos quizás podría interpretarse como neutro. Véase H. Amable, Op.cit., p.9.

26 N. A. G. L. de Terán y M.E. Asís observan en Op. cit., p. 301, "una progresiva reducción del esquema pronominal, pues es evidente que una sola forma - lo- tiende a absorber a varias. Es decir, el hecho de que lo invada progresivamente la jurisdicción de la-las, los puede ser explicado como un caso de economía morfológica."

27 S. Boretti de Macchia, en Ob.cit. \#1.1.2.4.3., cita este tipo de formas para Rosario. Afirma que se trata de un neutro.

28 J.M. Lope Blanch, en Observaciones sobre la sintaxis del español en México, UNAM, México, 1953, p. $21 \neq 5$, opina que "es considerado como muletilla de la acción que emana de un suj eto determinado." Véase además, Ch. Kany, Op. cit., p. 161 .

29 Ibídem Ch. Kany.

30 Comenta S.B. de Macchia en Op.cit., $\neq 1.1 .2 .2 .1 .4$. para el Litoral, que "A veces el elemento pronominal en función de objeto directo se acentúa prosódicamente cuando ocurre con las formas del imperativo ("dejamela"). En este aspecto, contrariando la regla prescripta, se acentúa el enclítico. El habla vulgar agrega a este fenómeno de orden suprasegmental una $(-n)$ final, por influencia de la desinencia verbal plural y como refuerzo de la idea de plural."

31 Con -mé-n también se encuentran ejemplos, pero en menor cantidad (12 casos).

32 Véase Ch. Kany, Op.cit., p. 145. 
33 Ch. Kany, en Op.cit., p. 144, informa que "La forma más corriente, también la más antigua es -sen por -se. En ello influye no sólo la $-\underline{n}$ del plural, sino también probablemente la terminación -sen (hablasen, tuviesen) del imperfecto de subjuntivo. La analogía se extendío luego a -me, -le, -10 , etc.. La -n interior, finalmente, desapareció por superflua."

34 Véase R.J. Cuervo, Apuntaciones críticas sobre el lenguaje bogotano, ICC, Bogotá, 1955, p. $346 \not 335$. S. Fernández, Gramática española, Madrid, 1951, p. $203 \# 108$; L. Flórez, Temas de Castellano, ICC, Bogotá, 1967, p. 64 .

35 En "Le por 'les', ¿un caso de economra moefológica?", en Boletín del I $\overline{C C}$, Bogotá, 1965; L. Contreras, "Usos pronominales no canónicos", en Estudios filológicos y linguiísticos, Homenaje a Angel Rosenblat en sus 70 años, Instituto Pedagógico, Caracas, 1974, \#2.5.; N.A. G. L.de Terán y M.E. Asis, Op. cit., p. 300 .

36 Véase S.B. de Macchia, Op.cit., $\not 1.1 .2 .4 .2$.

37 Jorge Cantero Sandoval en "Usos y significados de la forma pronominal /se/ en el habla culta de la ciudad de México", en Linguíistica y Educación, ALFA L, Lima, p. 251, lo clasifica, según sus funciones, en I Pronominal: Oblicuo; Reflexivo; Recíproco; y II No Pronominal Pasivo; Impersonal: Pasivo/Activo/Mixto; Cuasi-reflejo; Enfatico; Modificador del significado del verbo.

$38 \quad$ Ibíd.

$39 \quad$ Véase S. Gili y Gaya, Op.cit., $\$ 176$.

40 Se sigue en lo fundamental la clasificación de Cantero Sandoval, Op.cit., p. 252.

41 Véase L. Contreras, "Significados y funciones del se", en Zeitschrift für Romanische Philologie. T"ubingen, p. 306 , 
donde la autora plantea muy bien por qué se no puede ser sujeto, sino un determinante gramatical del verbo.

S. Glli y Gaya, Op.cit, pp. 76-77 $\$ 61$ y 128 $\$ 105$, considera que las oraciones a que nos referimos tienen como sujeto el impersonal se. También lo interpreta así $R$. Seco, Manuel de gramática española, Madrid, 1963, p. 184. L. Flórez, en Op. cit. p. 37, opina que en estos casos se "representa un sujeto real, activo pero indeterminado." J.M. Lope Blanch, en Op.cit., p. 91, dice que "en México no se conoce esta construcción, sino la pasiva refleja impersonal "se venden botellas". "Sin embargo, pareceque con el tiempo se introdujo en México, pues Cantero Sandoval en Op. cit., p. $254 \$ 2.2 .1$., la registra y comenta: "aparecib en mis materiales la conocida y censurada construcción en que no concuerda la frase nominal y el verbo ("se estudió muchas cosas", "se rectifica todos los datos en la otra má quina"."

43 No obstante ser el uso corriente de todos los hablantes, en el habla de nivel sociocultural alto - en estilo formal-, se cuida decir: "siento frío", o "hace frío".

44 Véase F. Pais, Algunos rasgos estilísticos de la lengua popular catamarqueña, U.N.T., Tucumán, 1953, p. 41.

45 Ch. Kany, Op.clt., p.p. 131 y 203, ubica el fenómeno especialmente en Santiago del Estero.

46 Nélida D. de Mirande en El español hablado en Rosario, U.N. del Litoral, Sta. Fe, 1968, p. 99, hace referencia , en cuanto a Rosario, a una forma que no se conoce en el NOA. Dice: "En el habla vulgar se sustituye frecuentemen te el "nos" por "los" : "No los vamos a ir","quedémoslos"'/ Este fenómeno es general en el habla vulgar de la Argenti na."

47 Véase T. Navarro Tomás, en Cuestionario lingüístico hispanoamericano, Buenos Aires, 1945, p. 421. 
48 F. Pais en Op.cit., opina que "¿Nos vayamos?, no es una simple exhortación ní sólo invitación: queda entre las dos formas transcriptas, mueho más compleja en contenido psicológico que cualquiera de ellas."

49 Véase Ch. Kany, Op.cit., p. 132.

50 Véase S. Gili y Gaya, Op.cit., $\not 58$; S. Fernăndez, Gra mática española $I$, Los sonidos, el nombrey el pronombre, Rev. de Occidente, Madrid, 1951, $\$ 104$ y S.B.de Macchia, Op.cit., $\not 1.1 .2 .4 .$, quien afirma que "El uso afectivo del pronombre personal se refleja claramente en el llamado "dativo de interés". Su empleo es frecuente en el uso culto tanto formal como informal."

51 Véase F. Pais, Op.cit., p. $43 \not 5$.

52 E1 acusativo intensivo es una forma vacía de significación, cuyo valor consiste en aportar mayor afectividad a la expresión.

53 Véase Pais, Op.cit., p. $42 \not 5$. Este autor lo llama "dativo de interés" a este dativo también llamado "ético" o "intensivo".

54 Véase M. Alvarez Nazario, El arcaísmo vulgar en el espanool de Puerto Rico, Puerto Rico, 1957, p. 115; Ch. Kany, Op.cit., p. 349.

55 S. Fernández, Op.cit., p. $193 \$ 104$, dice que entre los casos de pronombre átono intensivo se encuentra el llamado "dativo simpatético", o "posesivo" con le, verbos cuasirreflejos y sujeto de cosa.

56 J. M. Lope Blanch, Op.cit., p. 19 $\not 3$, comenta que 'tomando como modelo 'El se me acercó', se dice en México 'yo me le acerqué', en vez de 'yo me le acerqué a él'." $\mathrm{s}$. Fernández, Op.cit., p. $193 \not 104$, dice que "se debe este incremento en el empleo de los pronombres en dativo de 
Interés, al lenguaje, o mejor dicho, a la afectividad del lenguaje coloquial."

57 Véase mi libro Aspectos del habla en San Miguel de Tucumán, U.N.T., Tucumán, 1979, p. 91.

58 Véase L. Contreras, Op.cit., 1966, p. 305.

59 Ch. Kany, Op.cit., p. 237, habla de la tendencia opuesta: supresión del pronombre, de verbos que normalmente lo llevan. Por ej.: desayunar ("Yo desayuno muy poco"), corriente también en España; disparar ("Disparó hasta su casa") arcaico en España. (Estos son casos que se dan en todo el país). 